\title{
Evaluation and generalization of temperature-based methods for calculating evaporation
}

\author{
C.-Y. $\mathrm{Xu}^{1 *}$ and V. P. Singh ${ }^{2}$ \\ ${ }^{1}$ Department of Earth Sciences, Hydrology, Uppsala University, Villavägen 16, S-75236 Uppsala, Sweden \\ ${ }^{2}$ Department of Civil and Environmental Engineering, Louisiana State University, Baton Rouge, Louisiana 70803-6405, USA
}

\begin{abstract}
:
Seven temperature-based equations, each representing a typical form, were evaluated and compared for determining evaporation at two climatological stations (Rawson Lake and Atikokan) in north-western Ontario, Canada. The comparison was first made using the original constant values involved in each equation, and then using the recalibrated constant values. The results show that when the original constant values were used, larger biases existed for most of the equations for both stations. When recalibrated constant values were substituted for the original constant values, six of the seven equations improved for both stations. Using locally calibrated parameter values, all seven equations worked well for determining mean seasonal evaporation values. For monthly evaporation values, the modified Blaney-Criddle method produced least error for all months for both stations, followed by the Hargreaves and Thornthwaite methods. The Linacre, Kharrufa and Hamon methods showed a significant bias in September for both stations. With properly determined constant values, the modified Blaney-Criddle, the Hargreaves and Thornthwaite methods can be recommended for estimating evaporation in the study region, as far as temperature-based methods are concerned. Copyright (C) 2001 John Wiley \& Sons, Ltd.
\end{abstract}

KEY WORDS evaporation; temperature-based methods; north-western Ontario

\section{INTRODUCTION}

A knowledge of the magnitude and variation of evaporative losses is required in water resources planning and management, design of reservoirs, assessment of irrigation efficiency of existing projects, evaluation of future drainage requirements, quantification of deep percolation losses under existing water management practices, water supply requirements of proposed irrigation projects, and preparation of river forecasts, to name but a few. Potential evapotranspiration, together with precipitation, are the inputs to most hydrological models. There exist a multitude of methods, for measurement and estimation of evaporation, which can be classified into five groups: (i) water budget (e.g. Guitjens, 1982), (ii) mass-transfer (e.g. Harbeck, 1962), (iii) combination (e.g. Penman, 1948), (iv) radiation (e.g. Priestley and Taylor, 1972), and (v) temperaturebased (e.g. Thornthwaite, 1948; Blaney and Criddle, 1950). Overviews of many of these methods are found in review papers or books (e.g., Brutsaert, 1982; Singh, 1989; Jensen et al., 1990; Morton, 1990, 1994). The availability of many equations for determining evaporation, the wide range of data types needed, and the wide range of expertise needed to use the various equations correctly, make it difficult to select the most appropriate evaporation method even from a chosen group of methods for a given study.

There is, therefore, a need to analyse and compare the various forms of existing popular evaporation models belonging to each group, and to develop a generalized model form based on these models. Since 1996, a research programme has been underway with the main objective of evaluation and generalization of existing evaporation models. In an earlier study Singh and Xu (1997a) evaluated and compared 13

* Correspondence to: C.-Y. Xu, Uppsala University, Department of Earth Sciences, Hydrology, Villavägen 16, 75236 Uppsala, Sweden. E-mail: chong-yu.xu@hyd.uu.se 
evaporation equations that belonged to the category of mass-transfer method, and a generalized model form for that category was developed. Singh and Xu (1997b) further examined the sensitivity of mass-transfer-based evaporation equations to errors in daily and monthly input data. Xu and Singh (1998) analysed the dependence of evaporation on various meteorological variables at different time scales. More recently, radiation-based evaporation methods were evaluated and generalised in the study of Xu and Singh (2000). This paper reports some of the results of the ongoing research, i.e., to analyse, compare and generalize the various popular evaporation equations that belong to the category of temperature-based methods. This study is justified by the fact that temperature-based evaporation calculation methods, although widely criticized, are still widely used and have often been misused because of their simple nature. It is the authors' belief that if we cannot avoid using such methods, the best thing we can do is to analyse and compare them using the standard meteorological data and procedure, so as to provide the best equation forms to the users who have only temperature data available. Included in the study is a discussion of existing methods, generalization of model forms, evaluation and comparison of the different equation forms with the original values of the constants involved in each equation, and with the locally calibrated values of the constants. Finally, the overall applicability of the selected methods is examined and arranged in the order of their predictive ability for the study region.

\section{TEMPERATURE-BASED METHODS FOR ESTIMATION OF EVAPORATION}

\section{Discussion of existing methods}

Those evaporation $(E T)$ estimation methods that require only temperature as input variable are considered as temperature-based methods in this study. The temperature methods are some of the earliest methods for estimating ET. The relation of ET to air temperature dates back to the 1920s (see Jensen et al., 1990). Most temperature-based equations take the form

$$
E T=c T^{a}
$$

or

$$
E T=c_{1} d_{1} T\left(c_{2}-c_{3} h\right)
$$

in which $E T$ is evaporation or potential evapotranspiration, $T$ is air temperature, $h$ is a humidity term, $c, a$, $c_{1}, c_{2}, c_{3}$ are constants, $d_{1}$ is day length. Owing to the wide ranging inconsistency in meteorological data collection procedures and standards, many different evaporation equations, which have more or less the same model form, have been used by different authors. It is generally accepted that empirical formulae may be reliable in the areas and over the periods for which they were developed, but large errors can be expected when they are extrapolated to other climatic areas without recalibrating the constants involved in the formulae (Hounam, 1971). In order to alleviate these difficulties, this comparative study focuses on evaluating different equation forms instead of all existing equations. This consideration has, at least, two advantages:

(1) For a specific site of interest, it is the form of a given model that is more important (useful) than the predetermined values of the constants using the meteorological data measured at a previously reported site;

(2) it allows a comparison of all the model forms using the standard meteorological data measured at consistent heights and for the same periods.

This consideration results in the following seven temperature-based equations each representing a typical form, namely: Thornthwaite (1948), Linacre (1977), Blaney and Criddle (1950), Hargreaves (1975), Kharrufa (1985), Hamon (1961), and Romanenko (1961) methods. For the sake of completeness, these equations are briefly summarized in what follows. For a more complete discussion, the reader is referred to the references cited. 
Thornthwaite method. A widely used method for estimating potential evapotranspiration was derived by Thornthwaite (1948) who correlated mean monthly temperature with evapotranspiration as determined from water balance for valleys where sufficient moisture water was available to maintain active transpiration. In order to clarify the existing method, the computational steps of Thornthwaite equation are discussed.

1. The annual value of the heat index $I$ is calculated by summing monthly indices over a 12 -month period. The monthly indices are obtained from the equations

$$
i=\left(\frac{T_{\mathrm{a}}}{5}\right)^{1.51}
$$

and

$$
I=\sum_{j=1}^{12} i_{j}
$$

in which $I$ is the annual heat index, $i$ is the monthly heat index for the month $j$ (which is zero when the mean monthly temperature is $0{ }^{\circ} \mathrm{C}$ or less), $T_{\mathrm{a}}$ is the mean monthly air temperature $\left({ }^{\circ} \mathrm{C}\right)$ and $j$ is the number of months $(1-12)$.

2. The Thornthwaite general equation, Equation (4a) calculates unadjusted monthly values of potential evapotranspiration, $E T^{\prime}$ (in $\mathrm{mm}$ ), based on a standard month of 30 days, $12 \mathrm{~h}$ of sunlight/day

$$
E T^{\prime}=C\left(\frac{10 T_{\mathrm{a}}}{I}\right)^{a}
$$

in which $C=16$ (a constant) and $a=67.5 \times 10^{-8} I^{3}-77.1 \times 10^{-6} I^{2}+0.0179 I+0.492$.

The value of the exponent $a$ in the preceding equation varies from zero to 4.25 (e.g. Jain and Sinai, 1985), the annual heat index varies from zero to 160 , and $E T^{\prime}$ is zero for temperature below $0{ }^{\circ} \mathrm{C}$.

3. The unadjusted monthly evapotranspiration values $E T^{\prime}$ are adjusted depending on the number of days $N$ in a month $(1 \leqslant N \leqslant 31)$ and the duration of average monthly or daily daylight $d$ (in hours), which is a function of season and latitude.

$$
E T=E T^{\prime}\left(\frac{d}{12}\right)\left(\frac{N}{30}\right)
$$

in which $E T$ is the adjusted monthly potential evapotranspiration (mm), $d$ is the duration of average monthly daylight (hr); and $N$ is the number of days in a given month, 1-31 (days).

Thornthwaite's equation has been widely criticized for its empirical nature but is widely used. Because Thornthwaite's method of estimating $E T$ can be computed using only temperature, it has been one of the most misused empirical equations in arid and semi-arid irrigated areas where the requirement has not been maintained (Thornthwaite and Mather, 1955).

Linacre method. For the case of well-watered vegetation with an albedo of about 0.25, Linacre (1977) simplified the Penman formula to give the following expression for the evaporate rate

$$
E T=\frac{500 T_{\mathrm{m}} /(100-A)+15\left(T_{\mathrm{a}}-T_{\mathrm{d}}\right)}{\left(80-T_{\mathrm{a}}\right)}
$$

where $E T$ is the Linacre potential evapotranspiration (in $\mathrm{mm} /$ day), $T_{\mathrm{m}}=T+0.006 h, h$ is the elevation (m), $A$ is the latitude (degrees) and $T_{\mathrm{d}}$ is the mean dew-point. $T_{\mathrm{a}}, T_{\mathrm{m}}$ and $T_{\mathrm{d}}$ are in ${ }^{\circ} \mathrm{C}$. This formula requires only geographical data $(A$ and $h)$, the mean and the dew-point temperature. 
Blaney-Criddle method. The Blaney and Criddle (1959) procedure for estimating ET is well known in the western USA and has been used extensively elsewhere also (Singh, 1989). The usual form of the Blaney-Criddle equation converted to metric units is written as

$$
E T=k p\left(0 \cdot 46 T_{\mathrm{a}}+8 \cdot 13\right)
$$

where $E T$ is evapotranspiration from the reference crop (in $\mathrm{mm}$ ) for the period in which $p$ is expressed, $T_{\mathrm{a}}$ is mean temperature in ${ }^{\circ} \mathrm{C}, p$ is percentage of total daytime hours for the period used (daily or monthly) out of total daytime hours of the year $(365 \times 12)$, and $k$ is a monthly consumptive use coefficient, depending on vegetation type, location and season. According to Blaney and Criddle (1959) for the growing season (May to October) $k$ varies from 0.5 for orange tree to 1.2 for dense natural vegetation. In this study, an average value of 0.85 will be used for the preliminary comparison, and locally calibrated value will be used for the final evaluation.

Kharrufa method. Kharrufa (1985) derived an equation through correlation of ET/p and $T$ in the form of

$$
E T=0 \cdot 34 p T_{\mathrm{a}}^{1 \cdot 3}
$$

where $E T$ is the Kharrufa potential evapotranspiration (in $\mathrm{mm} /$ month) and $T_{\mathrm{a}}$ and $p$ have the same definitions as given earlier.

Hargreaves method. Hargreaves and Samani $(1982,1985)$ proposed several improvements for the Hargreaves (1975) equation for estimating grass-related reference $E T$. Because solar radiation data frequently are not available, Hargreaves and Samani $(1982,1985)$ recommended estimating $R_{\mathrm{S}}$ from extraterrestrial radiation, $R_{\mathrm{A}}$, and the difference between mean monthly maximum and minimum temperatures, $T D$ (in ${ }^{\circ} \mathrm{C}$ ). The resulting form of the equation is

$$
E T=0 \cdot 0023 R_{\mathrm{A}} T D^{1 / 2}\left(T_{\mathrm{a}}+17 \cdot 8\right)
$$

The extraterrestrial radiation, $R_{\mathrm{A}}$, is expressed in equivalent evaporation units. For a given latitude and day $R_{\mathrm{A}}$ is obtained from tables or may be calculated using a set of equations (see Jensen et al., 1990, p. 179). The only variable for a given location and time period is air temperature. Therefore, the Hargreaves method has become a temperature-based method.

Hamon method. Hamon (1961) derived a potential evapotranspiration method based on the mean air temperature and is expressed as

$$
E T=0.55 D^{2} P t
$$

where $E T$ is potential evapotranspiration (in inch/day), $D$ is the hours of daylight for a given day (in units of $12 \mathrm{~h})$ and $P t$ is a saturated water vapour density term calculated by

$$
P t=\frac{4.95 \mathrm{e}^{\left(0.062 T_{\mathrm{a}}\right)}}{100}
$$

where $T_{\mathrm{a}}$ is daily mean air temperature (in ${ }^{\circ} \mathrm{C}$ ).

Romanenko method. Romanenko (1961) derived an evaporation equation based on the relationship using mean temperature and relative humidity

$$
E T=0.0018\left(25+T_{\mathrm{a}}\right)^{2}(100-R h)
$$


where $T_{\mathrm{a}}$ is the mean air temperature (in ${ }^{\circ} \mathrm{C}$ ), $R h$ is the mean monthly relative humidity, which is calculated by:

$$
R h=\frac{e^{\circ}\left(T_{\mathrm{d}}\right)}{e^{\circ}\left(T_{\mathrm{a}}\right)}
$$

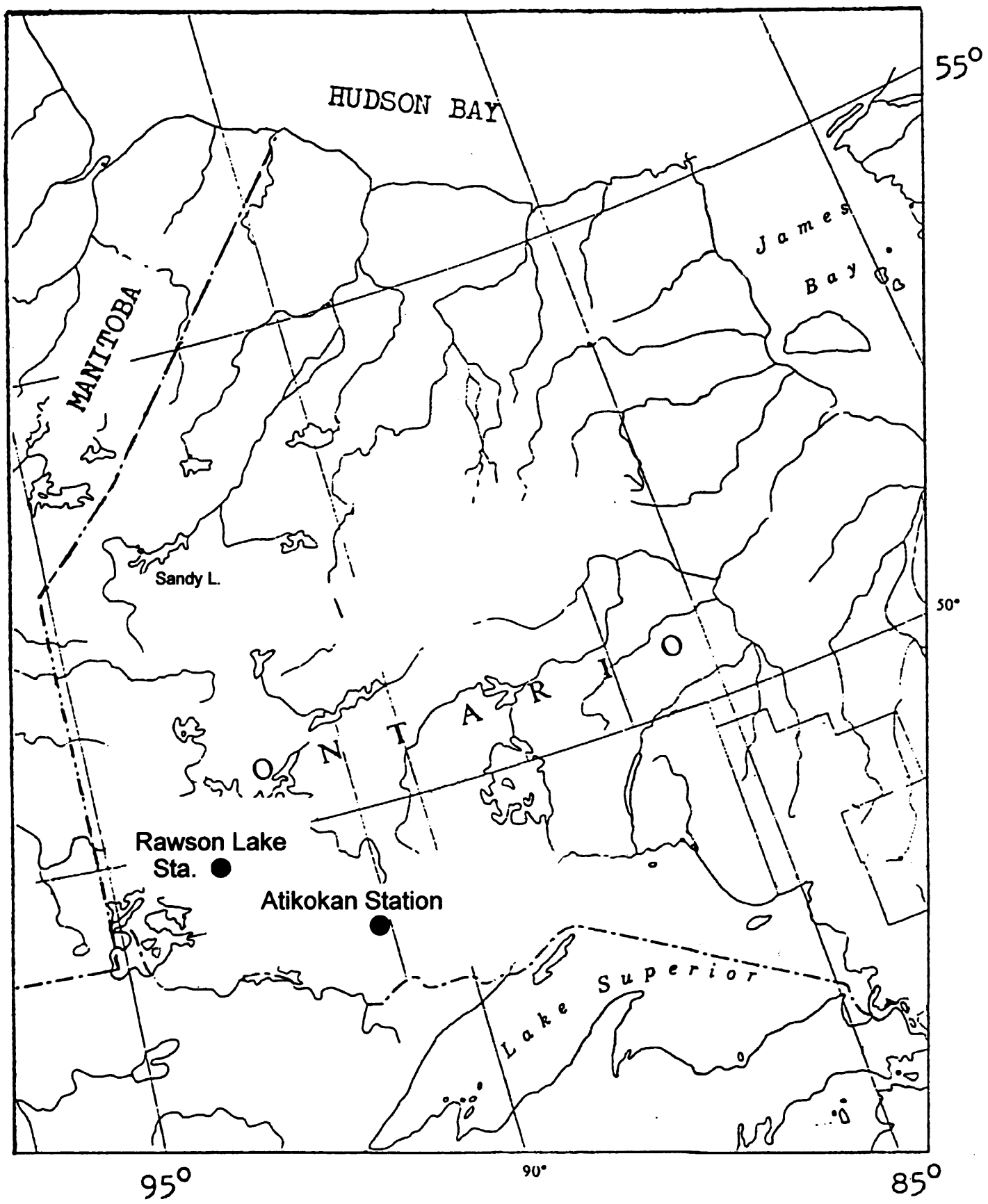

Figure 1. Geographical location of selected climatological stations in north-western Ontario 
in which $e^{\circ}(T)$ is the saturated vapour pressure calculated by (see Bosen, 1960)

$$
e^{\circ}(T)=33 \cdot 8679\left[(0 \cdot 00738 T+0 \cdot 8072)^{8}-0 \cdot 000019|1 \cdot 8 T+48|+0 \cdot 001316\right]
$$

\section{STUDY REGION AND DATA}

Two climatological stations were used for comparatively evaluating the aforementioned evaporation equation forms. These stations are located in north-western Ontario, Canada. The region is geographically defined by the borders of Manitoba, USA, Hudson Bay, James Bay and the easterly border as shown in Figure 1. The physiography of the area is typified by the occurrence of numerous lakes. It would be better to select lakes from different climatic settings, but this was not done owing to lack of data. According to Panu and Nguyen (1994), the mean annual precipitation for the region varies from a maximum of over $800 \mathrm{~mm}$ to less than $550 \mathrm{~mm}$ with an average value of $650 \mathrm{~mm}$. Mean annual temperature ranges from $-4^{\circ} \mathrm{C}$ to more than $3{ }^{\circ} \mathrm{C}$. The pertinent information on these stations is provided in Table I. Evaporation in this region is most significant during the summer season (June to September) and relatively insignificant during October through to May because temperature fluctuates near the freezing point during these months. Therefore, the mean monthly evaporation rates were computed and compared only for the months of June, July, August and September during each year.

\section{RESULTS AND DISCUSSIONS}

In the first stage of the comparative study, evaporation calculated by all seven methods with their original constant values was evaluated against the pan evaporation records for the two stations.

\section{Mean monthly and seasonal values}

The mean monthly and seasonal values of evaporation were computed using the various methods and the values calculated are shown in Table II together with the observed pan evaporation. In addition, this table also provides the percentage error of the estimate. The percentage error is also plotted for each station (Figure 2). It can be seen that the mean total differences (sum of June, July, August and September) between the pan evaporation and the seven estimation methods ranges from 0.3 to $-30.9 \%$ for station Rawson Lake and from 0 to $36.0 \%$ for station Atikokan, respectively. As far as the original constant values are used, the evaporation estimates by the Hamon method are considerably underestimated and entail the highest percentage error for both stations. The Thornthwaite method yields the second largest percentage error for both stations. When the mean total differences are considered, the Blaney-Criddle and Romanenko methods provide the least error at both stations. The Hargreaves and Kharrufa methods also provide good estimates for the Rawson Lake station.

It is also apparent that when the mean monthly values are concerned, the Blaney-Criddle method yields a big range of error in different months for both stations. The reason is that the same value $(0 \cdot 85)$ was used

Table I. General information on two climatological stations in north-western Ontairo

\begin{tabular}{lccccr}
\hline Station & \multicolumn{4}{c}{ Mean monthly values (June-September) } & Period \\
\cline { 2 - 5 } & $\begin{array}{c}\text { Air temperature } \\
\left({ }^{\circ} \mathrm{C}\right)\end{array}$ & $\begin{array}{c}\text { Dew point } \\
\text { temperature }\left({ }^{\circ} \mathrm{C}\right)\end{array}$ & $\begin{array}{c}\text { Wind velocity } \\
(\mathrm{km} / \mathrm{h})\end{array}$ & $\begin{array}{c}\text { Class A pan } \\
\text { evaporation }(\mathrm{mm})\end{array}$ & $1968-1982$ \\
\hline Atikokan & 14.53 & 9.92 & 7.63 & 126.88 & $1971-1982$ \\
Rawson Lake & 15.98 & 9.25 & 9.61 & 130.49 & 1970 \\
\hline
\end{tabular}


EVAPORATION CALCULATION

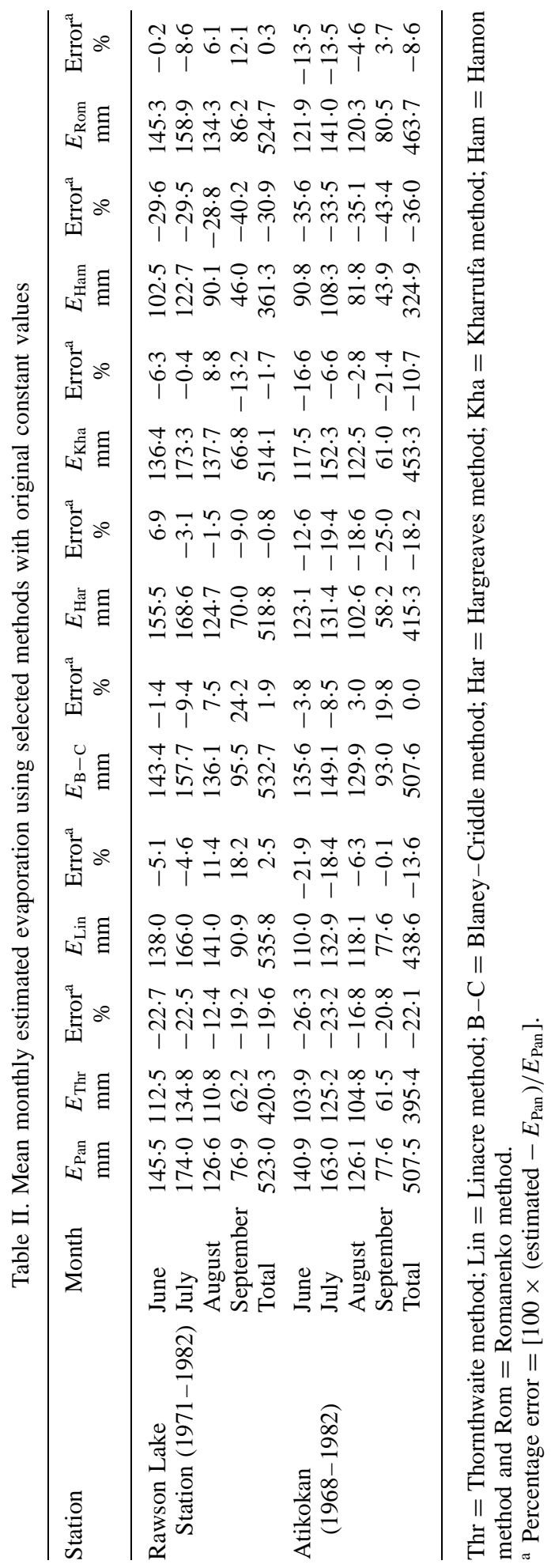




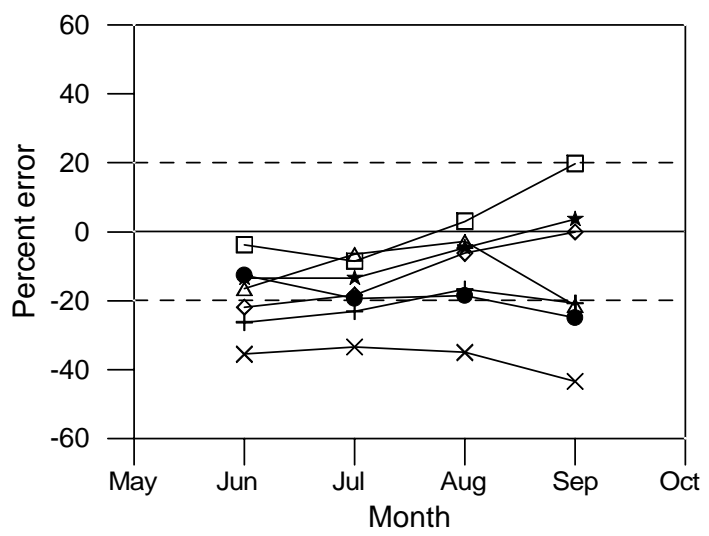

Atikokan Station (1968-1982)

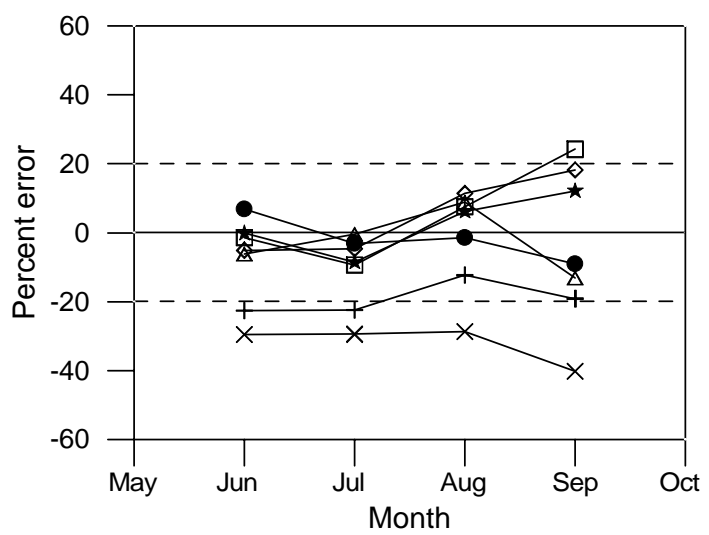

Rawson Lake Station (1971-1982)

Figure 2. Percentage error in evaporation estimates at two selected stations using original parameter values. (Line with plus for Thornthwaite, line with diamond for Linacre, line with square for Blaney-Criddle, line with circle for Hargreaves, line with triangle for Kharrufa, line with cross for Hamon, line with star for Romanenko)

Table III. Regression relationships between pan evaporation and estimated evaporation using selected methods with original constant values

\begin{tabular}{lccccccc}
\hline \multirow{2}{*}{ Methods } & \multicolumn{3}{c}{ Atikokan Station } & & \multicolumn{3}{c}{ Rawson Lake Station } \\
\cline { 2 - 3 } & Slope & Intercept & $R^{2}$ & & Slope & Intercept & $R^{2}$ \\
\hline Thornthwaite & 1.26 & 3.69 & 0.81 & & 1.31 & -6.82 & 0.83 \\
Linacre & 1.40 & -26.73 & 0.82 & & 1.22 & -33.00 & 0.87 \\
Hargreaves & 1.10 & 12.40 & 0.89 & & 0.94 & 7.93 & 0.90 \\
Kharrufa & 0.86 & 29.68 & 0.80 & & 0.87 & 18.06 & 0.82 \\
Hamon & 1.31 & 20.78 & 0.85 & & 1.26 & 17.12 & 0.85 \\
Romanenko & 1.26 & -19.55 & 0.86 & & 1.03 & -5.01 & 0.77 \\
Blaney-Criddle & 1.48 & -59.80 & 0.85 & 1.54 & -74.18 & 0.83 \\
\hline
\end{tabular}

for parameter $k$, the monthly consumption use coefficient. In the next stage of the study different values will be determined for each month. 

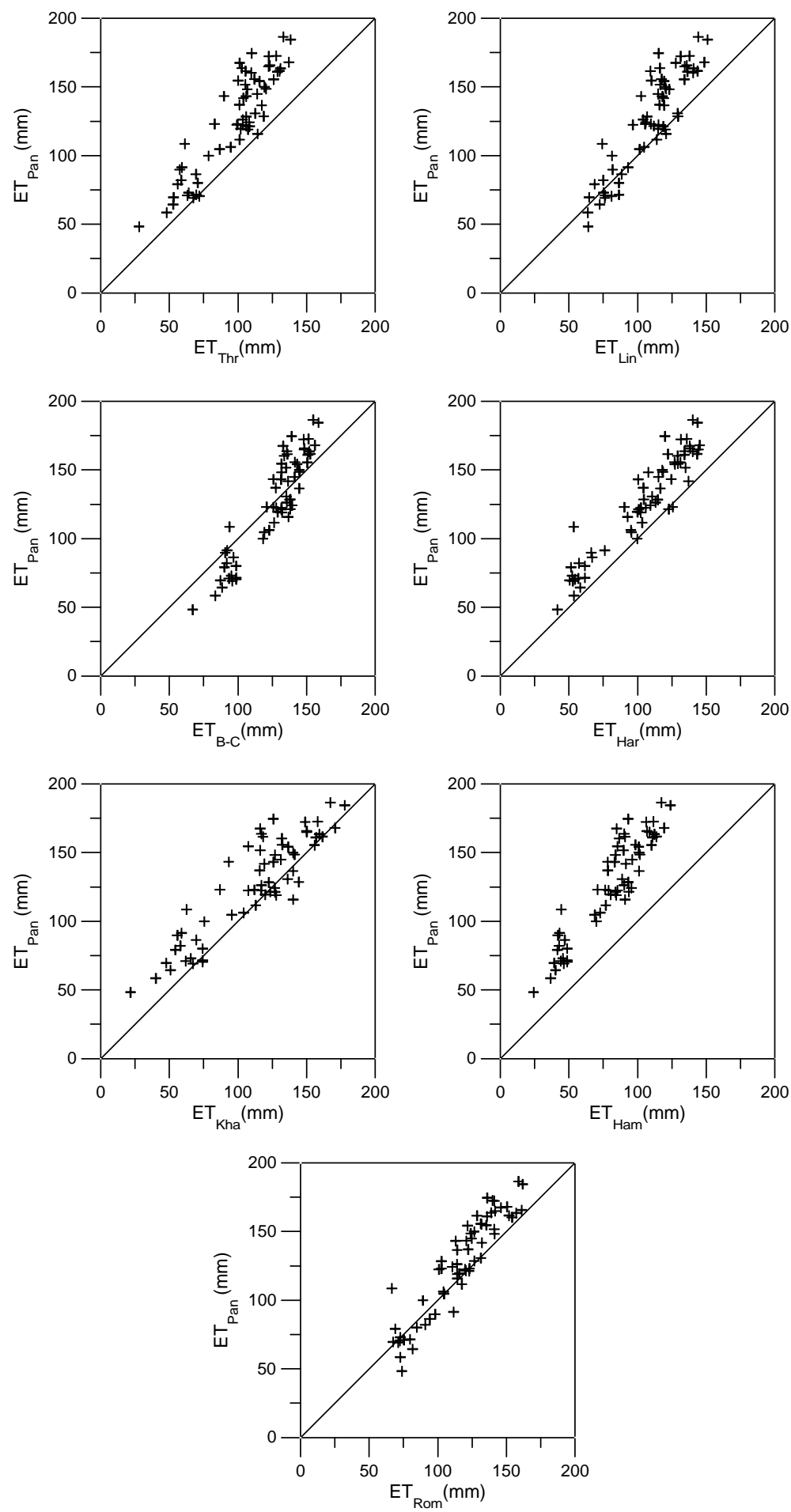

Figure 3. Comparison of pan $E T$ with estimated $E T$ for $\mathrm{Thr}=$ Thornthwaite method; Lin $=$ Linacre method; B-C = Blaney-Criddle method; Har = Hargreaves method; Kha $=$ Kharrufa method, Ham $=$ Hamon method and Rom $=$ Romanenko method The original constant values were used in the calculation 


\section{Correlation of monthly estimates between methods}

The monthly evaporation values computed using the different methods were analysed to correlate with pan evaporation using a linear regression equation

$$
Y=m X+c
$$

where $Y$ represents $E_{\text {Pan }}$ and $X$ is the $E T$ estimated from the above-mentioned seven methods, and $m$ and $c$ are constants representing the slope and intercept, respectively. The results of regression analysis are shown in Table III. The cross-correlation $\left(R^{2}\right)$ between pan evaporation and the evaporation computed using other methods is also presented the Table III. For illustrative purposes, the estimated $E T$ from the above-mentioned seven methods are plotted against pan evaporation for the station Atikokan (Figure 3).

It is seen from Figure 3 and Table III that:

(1) as far as the $R^{2}$ values are concerned, all $E T$ estimates correlated well with pan evaporation with $R^{2}$ values varying from 0.77 to 0.90 . The Hargreaves method has the highest $R^{2}$ value $(0.90$ and 0.89 for stations Rawson Lake and Atikokan, respectively), followed by the Hamon method ( 0.85 for both stations). The Romanenko method gives the second highest $R^{2}$ value for station Atikokan $(0 \cdot 86)$ and lowest value for station Rawson Lake (0.77).

(2) When slope and intercept are compared, large biases exist for most the cases, i.e., either the slopes $(m)$ are significantly different from 1 or the intercepts $(c)$ are significantly different from 0 or both, except the Hargreaves and Romanenko methods for station Rawson Lake and the Hargreaves method for station Atikokan. This particular case study shows that using the original constant values of empirical formulae for other climatic areas leads to large biases in estimating monthly evaporation.

\section{Modifications to equations}

The previous discussion shows that empirical formulae, as used in this study, may be reliable in the areas and over the periods for which they were developed, but large errors, i.e., higher values of intercepts and larger biases of regression slopes, can be expected when they are extrapolated to other climatic areas without recalibrating the constants involved in the formulae. Accordingly, modifications were made to the original equations used here to improve results. The constant values of 16, 500, 0.34, 0.0023, 0.55 and 0.0018 used in Equations (4a), (5), (7), (8), (9), and (11), respectively, are recalibrated. As for the Blaney-Criddle equation, different values of parameter $k$ were determined for each month. There are two reasons for this consideration. First, the previous results show that using the same value of $k=0.85$ for each month resulted in the highest

Table IV. Comparison of parameter values before and after calibration

\begin{tabular}{|c|c|c|c|c|}
\hline \multirow[t]{3}{*}{ Method } & \multirow{3}{*}{$\begin{array}{c}\text { Equation } \\
\text { number }\end{array}$} & \multicolumn{3}{|c|}{ Parameter Values } \\
\hline & & \multirow[t]{2}{*}{ Original } & \multicolumn{2}{|c|}{ Recalibrated } \\
\hline & & & Rawson Lake & Atikokan \\
\hline Thornthwaite & $4 a$ & 16 & 20 & $20 \cdot 5$ \\
\hline Linacre & 5 & 500 & 488 & 615 \\
\hline Hargreaves & 8 & 0.0023 & 0.0023 & $0 \cdot 0028$ \\
\hline Kharrufa & 7 & $0 \cdot 34$ & 0.34 & $0 \cdot 37$ \\
\hline Hamon & 9 & 0.55 & 0.79 & $0 \cdot 85$ \\
\hline Romanenko & 11 & $0 \cdot 0018$ & 0.0018 & $0 \cdot 0020$ \\
\hline \multirow{4}{*}{ Blaney-Criddle } & 6 & $0 \cdot 85$ & 0.88 (June) & 0.86 (June) \\
\hline & & & 0.93 (July) & 0.94 (July) \\
\hline & & & 0.86 (August) & 0.79 (August) \\
\hline & & & 0.71 (September) & 0.69 (September) \\
\hline
\end{tabular}


EVAPORATION CALCULATION

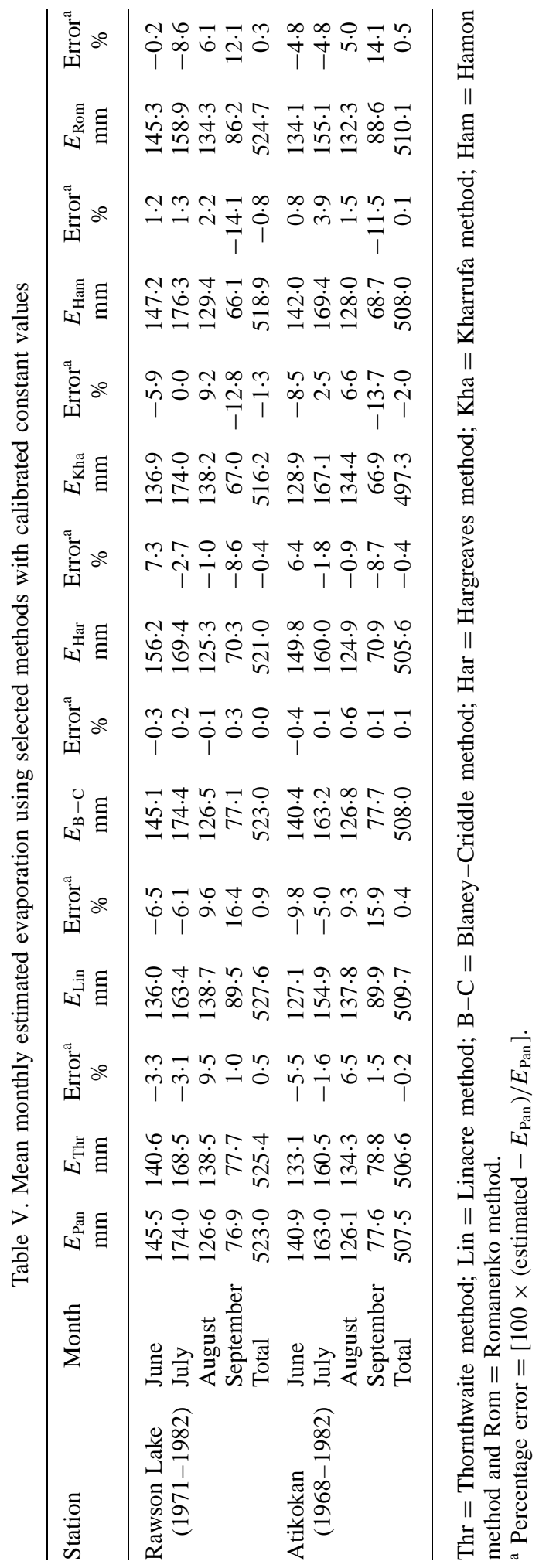


intercept value and most biased slope values among all the methods (see Table III). Second, parameter $k$ in the Blaney-Criddle equation is the monthly consumptive use coefficient and varies with season. A comparison of the original model parameter values with recalibrated values is shown in Table IV.

The mean monthly and seasonal (June-September) values calculated by these equations with the calibrated constant values are shown in Table V. The mean monthly percent errors as shown in Table V are also plotted in Figure 4. The same regression analysis was carried out for the monthly values of evaporation and the results are shown in Table VI. For illustrative purposes, the estimated ET from the above-mentioned seven methods are plotted against pan evaporation for the station Atikokan (Figure 5).

A comparison of Tables V and II, and Figures 4 and 2 shows a significant improvement in six of the seven models for station Rawson Lake, and in all the cases for station Atikokan. Using the calibrated constant values in the equations, all seven methods are able to simulate the mean seasonal evaporation values (sum of values for months June, July, August and September) perfectly, with a maximum error of $2 \%$ in the case of the Kharrufa method for station Atikokan. The calculated mean monthly evaporation values are also improved significantly for most of the methods in both stations (see Table V and Figure 4). The best results are given by the Blaney-Criddle method for both stations,

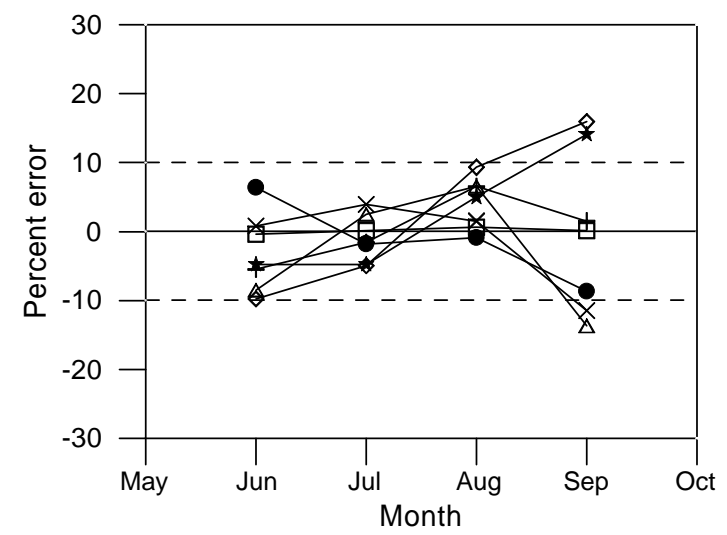

Atikokan Station (1968-1982)

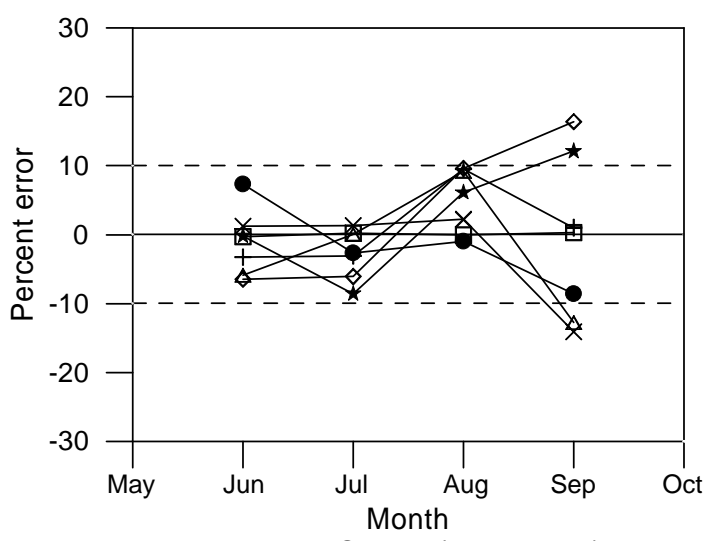

Rawson Lake Station (1971-1982)

Figure 4. Percentage error in evaporation estimates at two selected stations using calibrated parameter values. Line with plus sign for Thornthwaite, line with diamond for Linacre, line with square for Blaney-Criddle, line with circle for Hargreaves, line with triangle for Kharrufa, line with cross for Hamon, line with star for Romanenko 
Table VI. Regression relationships between pan evaporation and estimated evaporation using selected methods with locally calibrated constant values

\begin{tabular}{|c|c|c|c|c|c|c|}
\hline \multirow[t]{2}{*}{ Methods } & \multicolumn{3}{|c|}{ Atikokan Station } & \multicolumn{3}{|c|}{ Rawson Lake Station } \\
\hline & Slope & Intercept & $R^{2}$ & Slope & Intercept & $R^{2}$ \\
\hline Thornthwaite & $1 \cdot 00$ & $0 \cdot 42$ & $0 \cdot 82$ & 1.05 & $-6 \cdot 82$ & 0.83 \\
\hline Linacre & $1 \cdot 16$ & $-21 \cdot 21$ & 0.79 & $1 \cdot 24$ & $-33 \cdot 14$ & $0 \cdot 87$ \\
\hline Hargreaves & 0.90 & $13 \cdot 20$ & $0 \cdot 89$ & $0 \cdot 94$ & $7 \cdot 93$ & $0 \cdot 90$ \\
\hline Kharrufa & 0.79 & $28 \cdot 20$ & $0 \cdot 80$ & 0.87 & $18 \cdot 01$ & $0 \cdot 82$ \\
\hline Hamon & $0 \cdot 84$ & $20 \cdot 73$ & $0 \cdot 85$ & $0 \cdot 88$ & $17 \cdot 12$ & $0 \cdot 85$ \\
\hline Romanenko & $1 \cdot 12$ & -15.96 & $0 \cdot 86$ & 1.03 & $-5 \cdot 01$ & 0.77 \\
\hline Blaney-Criddle & $1 \cdot 01$ & -1.65 & $0 \cdot 85$ & 1.02 & -3.09 & $0 \cdot 84$ \\
\hline
\end{tabular}

followed by the Hargreaves and Thornthwaite methods. The percentage errors of estimate for September are relatively high for most of the methods for both stations. The largest mean monthly percentage errors are $\mathbf{1 6 . 4 \%}$ and $\mathbf{1 5 . 9 \%}$ for stations Rawson Lake and Atikokan, respectively, with the Linacre method.

A comparison of Tables VI and III, and Figures 5 and 3 shows that: (i) there is no significant change concerning the $R^{2}$ values using the calibrated constant values in the equations; and (ii) the slope $(m)$ and intercept $(c)$ of the regression equations improved or significantly improved in five of the seven cases for station Atikokan, and in three of the seven cases for Rawson Lake. Other cases have no significant changes. The seasonal bias (i.e. higher intercepts and non-unit values of slopes) is still a problem for the Linacre, Kharrufa and Hamon methods. It can be observed from the above discussion that all seven methods can calculate well the mean seasonal evaporation with locally determined parameter values. As far as monthly evaporation estimates are concerned, it is evidently clear that the modified Blaney-Criddle method produces least percent error of all the months at both stations, followed by the Hargreaves and Thornthwaite methods. The Linacre, Kharrufa and Hamon methods are not recommended for evaporation estimation in the study region.

\section{SUMMARY AND CONCLUSIONS}

In this study, seven temperature-based equations, each with a typical form, were evaluated using meteorological data from two climatological stations in north-western Ontario, Canada, for calculating evaporation. The evaluation and comparison were made based on both the original constant values involved in each equation and the recalibrated constant values. In case of using original constant values of the seven original equations evaluated, the Blaney-Criddle equation resulted in mean seasonal evaporation values that agreed most closely with pan evaporation values. Large errors resulted for the Thornthwaite and Hamon methods. Underestimation was the common problem. By substituting recalibrated constant values for the original constant values, six of the seven equations improved for both stations, and all seven equations worked well for determining the mean seasonal evaporation values. As far as the monthly values were concerned, the modified Blaney-Criddle method produces least percentage error of all the months at both stations, followed by the Hargreaves and Thornthwaite methods. With properly determined constant values, the Blaney-Criddle, Hargreaves and Thornthwaite methods can be used for calculating evaporation in the study region as far as temperature-based methods are concerned. 

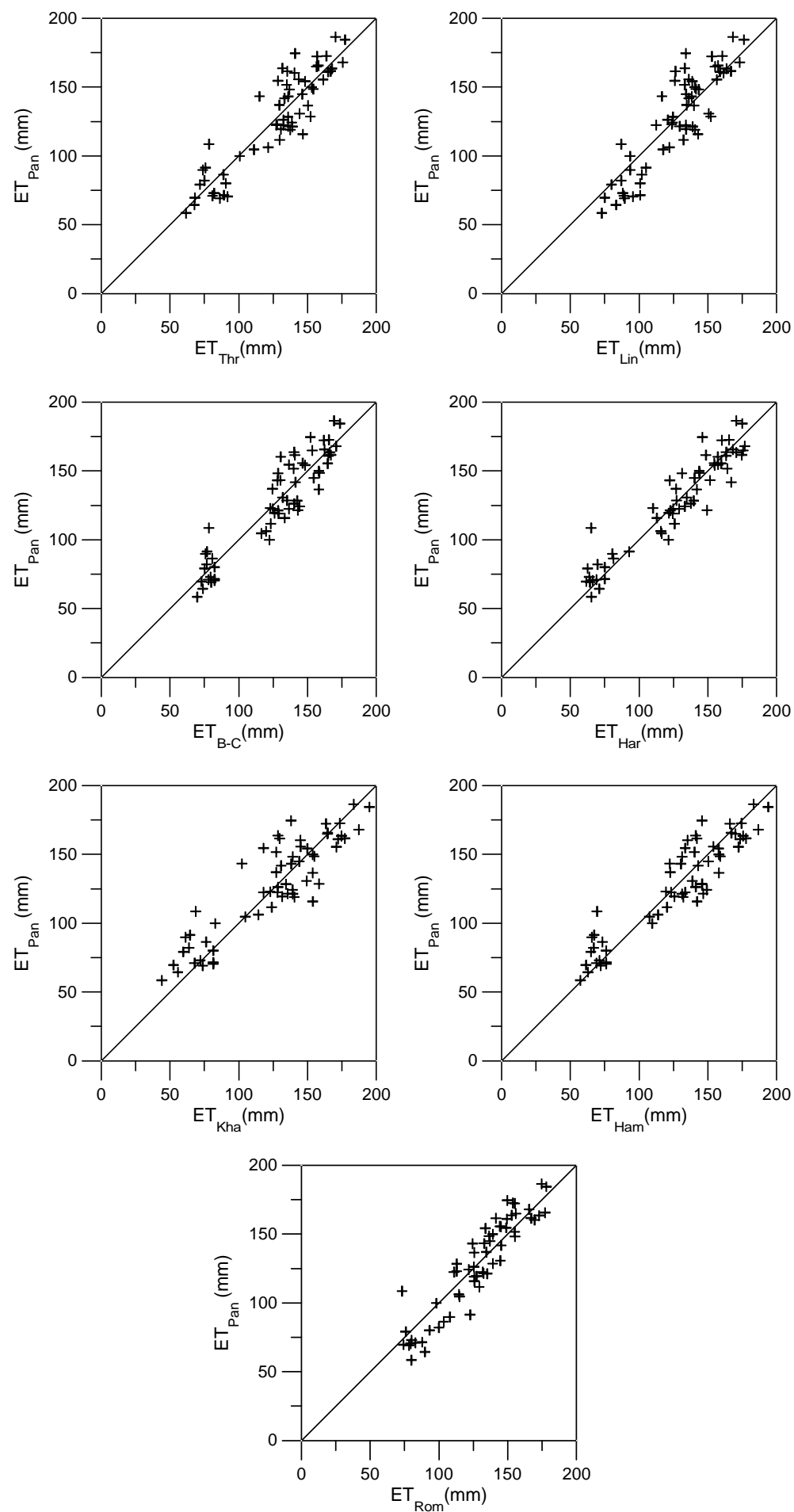

Figure 5. Comparison of pan $E T$ with estimated $E T$ for $\mathrm{Thr}=$ Thornthwaite method; Lin $=$ Linacre method; B-C $=$ Blaney-Criddle method; Har = Hargreaves method; Kha $=$ Kharrufa method, Ham $=$ Hamon method and Rom $=$ Romanenko method. The recalibrated constant values were used in the calculation 


\section{ACKNOWLEDGMENTS}

The authors thank Professor U. S. Panu of Lakehead University for his kind assistance in providing all the necessary data and information. The NFR (Swedish Natural Science Research Council) partially financed the study.

\section{REFERENCES}

Blaney HF, Criddle WD. 1950. Determining Water Requirements in Irrigated Areas from Climatological Irrigation Data. Technical Paper No. 96, US Department of Agriculture, Soil Conservation Service, Washington, D.C., 48 pp.

Bosen JF. 1960. A formula for approximation of saturation vapor pressure over water. Monthly Weather Review 88(8): 275-276.

Brutsaert W. 1982. Evaporation into the Atmosphere. D. Reidel: Dordrecht.

Guitjens JC. 1982. Models of alfalfa yield and evapotranspiration. Journal of the Irrigation and Drainage Division, Proceedings of the American Society of Civil Engineers 108(IR3): 212-222.

Hamon WR. 1961. Estimating potential evapotranspiration. Journal of Hydraulics Division, Proceedings of the American Society of Civil Engineers 871: 107-120.

Harbeck GE. 1962. A practical field technique for measuring reservoir evaporation utilizing mass-transfer theory. Geological Survey Professional Paper 272-E: 101-105.

Hargreaves GH. 1975. Moisture availability and crop production. Transactions of the American Society of Agricultural Engineers 18: 980-984.

Hargreaves GH, Samni ZA. 1982. Estimation of potential evapotranspiration. Journal of Irrigation and Drainage Division, Proceedings of the American Society of Civil Engineers 108: 223-230.

Hargreaves GH, Samni ZA. 1985. Reference crop evapotranspiration from temperature. Transactions of the American Society of Agricultural Engineers.

Hounam CE. 1971. Problems of Evaporation Assessment in the Water Balance. Report on WMO/IHP Projects, No. 13, World Health Organization: Geneva.

Jensen ME, Burman RD, Allen RG. 1990. Evapotranspiration and Irrigation Water Requirements. American Society of Civil Engineers: New York.

Jain PK, Sinai G. 1985. Evapotranspiration model for semiarid regions. Journal of Irrigation and Drainage Engineering 111(4): 369-379.

Kharrufa NS. 1985. Simplified equation for evapotranspiration in arid regions. Beiträge zur Hydrologie Sonderheft 5.1: 39-47.

Linacre ET. 1977. A simple formula for estimating evaporation rates in various climates, using temperature data alone. Agricultural Meteorology 18: 409-424.

Morton FI. 1990. Studies in evaporation and their lessons for the environmental sciences. Canadian Water Resources Journal 15(3): $261-285$.

Morton FI. 1994. Evaporation research - a critical review and its lessons for the environmental sciences. Critical Reviews in Environmental Science and Technology 24(3): 237-280.

Panu US, Nguyen T. 1994. Estimation of mean areal evaporation in northwestern Ontario. Canadian Water Resources Journal 19(1): 69-82.

Penman HL. 1948. Natural evaporation from open water, bare soil and grass. Proceedings, Royal Society of London 193: 120-145.

Priestley CHB, Taylor RJ. 1972. On the assessment of the surface heat flux and evaporation using large-scale parameters. Monthly Weather Review 100: 81-92.

Romanenko VA. 1961. Computation of the autumn soil moisture using a universal relationship for a large area. Proceedings Ukrainian Hydrometeorological Research Institute (Kiev) 3.

Singh VP. 1989. Hydrologic Systems, Vol. II, Watershed Modelling. Prentice-Hall: Englewood Cliffs, New Jersey.

Singh VP, Xu C-Y. 1997a. Evaluation and generalization of 13 equations for determining free water evaporation. Hydrological Processes 11: $311-323$.

Singh VP, Xu C-Y. 1997b. Sensitivity of mass transfer-based evaporation equations to errors in daily and monthly input data. Hydrological Processes 11: 1465-1473.

Thornthwaite CW. 1948. An approach toward a rational classification of climate. Geographical Review 38: 55-94.

Thornthwaite CW, Mather JR. 1955. The water budget and its use in irrigation. In Water, The Yearbook of Agriculture. US Department of Agriculture: Washington DC; 346-358.

Xu C-Y, Singh VP. 1998. Dependence of evaporation on meteorological variables at different time-scales and intercomparison of estimation methods. Hydrological Processes 12: 429-442.

Xu C-Y, Singh VP. 2000. Evaluation and generalization of radiation-based methods for calculating evaporation. Hydrological Processes 14: 339-349. 